\title{
Metallurgical optimisation of PM superalloy N19
}

\author{
Didier Locq ${ }^{1, \text { a }}$, Loeïz Nazé ${ }^{2}$, Jean-Michel Franchet ${ }^{3}$, Pierre Caron ${ }^{1}$, Alice Dumont ${ }^{2}$, Alain Köster ${ }^{2}$, \\ and Jean-Yves Guédou ${ }^{4}$ \\ ${ }^{1}$ Onera - The French Aerospace Lab, 92322 Châtillon, France \\ ${ }^{2}$ MINES ParisTech, Centre des Matériaux CNRS UMR 7633, BP. 87, 91003 Evry Cedex, France \\ 3 Snecma Gennevilliers, 171 Bld. Valmy, BP. 31, 92702 Colombes Cedex, France \\ ${ }^{4}$ Snecma Villaroche, 77550 Moissy-Cramayel, France
}

\begin{abstract}
Microstructures of the new PM superalloy N19 have been investigated for various heat treatments in order to reach the best compromise between static strength and cyclic resistance. One subsolvus and several supersolvus heat treatments were applied to produce fine $(7 \mu \mathrm{m})$ and medium $(25 \mu \mathrm{m})$ grain sizes, respectively. The alloy is shown to be quite sensitive to the cooling conditions after solutioning as the $\gamma^{\prime}$ hardening precipitates, both secondary and tertiary, have a direct influence on mechanical properties. Two cooling conditions after solutioning produce a high crack propagation resistance at $650{ }^{\circ} \mathrm{C}$ with dwell time cycles, which is one of the basic requirements. The low cycle fatigue behaviour appears to be correlated to the grain size, which determines the origin of crack initiation (from ceramic inclusions or not). The other mechanical properties (tensile, creep) remain above target levels. Despite the medium size grain microstructure in the supersolvus condition, a high level of mechanical strength is observed in N19 at elevated temperature. It is understood that further improvement in properties can be achieved by developing coarse grain microstructures.
\end{abstract}

\section{Introduction}

Disks manufactured via the powder metallurgy (PM) route have superior properties owing to the better control of elemental segregation and finer grain size compared to those that can be achieved via the conventional cast and wrought process. However PM disks exhibit several challenges, which include cleanliness of the powder, consolidation into a defect-free structure and a tailored heat treatment for producing the desired properties.

Work performed by the 2000's within the Defence Research Programme "PROMETHEE", which was aimed at technologies for an improved military engine, identified a new PM superalloy for disks [1] that appeared significantly more resistant than the N18 reference one regarding both temperature capability and strength. This new disk alloy was developed in the frame of a consortium comprised of ONERA, Armines and Snecma. The alloy was designed to exhibit an improved crack propagation and fatigue resistant microstructure, combined with a capability for coarse grain microstructures to tolerate high temperatures in disk rims that are prone to creep damage. To achieve the desired combination of properties up to $700{ }^{\circ} \mathrm{C}$, the resultant superalloy, known as N19, needs to be optimised as regards its microstructure, which can be achieved through careful control of the grain size and of the $\gamma^{\prime}$ hardening precipitate distributions and morphologies. The definition of an optimum supersolvus heat treatment

\footnotetext{
${ }^{a}$ Corresponding author: didier. locq@onera.fr
}

leading to the best performances within the operating conditions of interest is described hereinafter.

\section{Material and heat treatments}

The material used in this study was as-forged PM turbine disk N19 alloy [1]. Argon atomised powder was produced, screened $(<53 \mu \mathrm{m})$, canned and hot isostatically pressed (HIP) at $1160^{\circ} \mathrm{C}$ and $100 \mathrm{MPa}$ for three hours. Three HIPed billets were then extruded at $1070{ }^{\circ} \mathrm{C}$ with a 5.5 extrusion ratio (Aubert \& Duval production). Segments cut from extruded bars were isothermally forged by Snecma into pancakes about $190 \mathrm{~mm}$ diameter and $28 \mathrm{~mm}$ thick. The composition of N19 alloy is given in Table 1.

The fraction of strengthening $\gamma^{\prime}$ phase was estimated to be within the $0.40-0.45$ range. The $\gamma^{\prime}$ solvus temperature of $\mathrm{N} 19$ was determined to be about $1150^{\circ} \mathrm{C}$. The density of this alloy is $8.32 \mathrm{~g} \cdot \mathrm{cm}^{-3}$. The heat treatment sequences applied to obtain the different microstructural variants of N19 are listed in Table 2. All these heat treatments (HT) were conducted at Snecma in a vacuum furnace equipped with a high pressure gas quenching system.

For the subsolvus condition, specimens were heat treated at $1120^{\circ} \mathrm{C}$ for four hours. For the four supersolvus conditions, specimens were heat treated at $1180^{\circ} \mathrm{C}$ for two hours. The different cooling paths were controlled by the high pressure gas quenching system of the furnace. The reference cooling rate $\left(100^{\circ} \mathrm{C} \cdot \mathrm{min}^{-1}\right)$ was applied after the subsolvus (SUB) or the supersolvus (SUPER) HT. After the supersolvus $\mathrm{HT}$, a slower cooling at $60^{\circ} \mathrm{C} \cdot \mathrm{min}^{-1}$

This is an Open Access article distributed under the terms of the Creative Commons Attribution License 4.0, which permits unrestricted use, distribution, and reproduction in any medium, provided the original work is properly cited. 
Table 1. Composition of N19 alloy in weight percent.

\begin{tabular}{|c|c|c|c|c|c|}
\hline Ni & Co & Cr & Mo & W & Al \\
\hline Bal. & 11.8 & 12.9 & 4.7 & 3.2 & 2.5 \\
\hline Ti & Nb & Hf & B & C & Zr \\
\hline 3.8 & 1.6 & 0.3 & 0.015 & 0.022 & 0.06 \\
\hline
\end{tabular}

Table 2. Heat treatment conditions.

\begin{tabular}{|c|c|c|c|}
\hline $\begin{array}{l}\text { Heat } \\
\text { treatment }\end{array}$ & $\begin{array}{c}\text { Solution } \\
\text { treatment }\end{array}$ & $\begin{array}{c}\text { Cooling } \\
\text { rate }\end{array}$ & $\begin{array}{c}\text { Aging } \\
\text { treatment }\end{array}$ \\
\hline SUB & $1120^{\circ} \mathrm{C}-4 \mathrm{~h}$ & $100^{\circ} \mathrm{C} \cdot \min ^{-1}$ & $750{ }^{\circ} \mathrm{C}-8 \mathrm{~h}$ \\
\hline SUPER & \multirow{4}{*}{$1180^{\circ} \mathrm{C}-2 \mathrm{~h}$} & $100^{\circ} \mathrm{C} \cdot \min ^{-1}$ & \multirow{3}{*}{$775^{\circ} \mathrm{C}-8 \mathrm{~h}$} \\
\hline SUPER-SC & & $60^{\circ} \mathrm{C} \cdot \min ^{-1}$ & \\
\hline SUPER-FC & & $240^{\circ} \mathrm{C} \cdot \mathrm{min}^{-1}$ & \\
\hline SUPER-TR & & $\begin{array}{l}15^{\circ} \mathrm{C} \cdot \min ^{-1} \\
\text { to } 1080^{\circ} \mathrm{C} \text { then } \\
100^{\circ} \mathrm{C} \cdot \mathrm{min}^{-1}\end{array}$ & $750^{\circ} \mathrm{C}-8 \mathrm{~h}$ \\
\hline
\end{tabular}

Table 3. Influence of the heat treatments on the N19 microstructure.

\begin{tabular}{|c|c|c|c|}
\hline $\begin{array}{l}\text { Heat } \\
\text { treatment }\end{array}$ & $\begin{array}{c}\text { Grain size } \\
(\mu \mathrm{m})\end{array}$ & $\begin{array}{r}\text { Primary } \gamma^{\prime} \\
(\text { area } \%)\end{array}$ & $\begin{array}{c}\text { Secondary } \\
\gamma^{\prime} \text { size }(\mathrm{nm})\end{array}$ \\
\hline SUB & 6 & 7.4 & 132 \\
\hline SUPER & \multirow{4}{*}{$22-25$} & \multirow{4}{*}{0} & 214 \\
\hline SUPER-SC & & & 268 \\
\hline SUPER-FC & & & 150 \\
\hline SUPER-TR & & & $545+124$ \\
\hline
\end{tabular}

(SUPER-SC), a faster cooling at $240^{\circ} \mathrm{C} \cdot \mathrm{min}^{-1}$ (SUPERFC) or a two-rate cooling (SUPER-TR) was applied. Finally, the specimens were aged for 8 hours in the 750$775^{\circ} \mathrm{C}$ range (depending on the hardening peak previously determined using micro-hardness tests).

\section{Effects of heat treatments on microstructure}

\subsection{Experimental procedures}

The microstructural examinations were performed on radial cross-sections of samples cut from room temperature tensile specimens (in low stress loading sections). The main microstructural features studied here are the grain size, the primary $\gamma^{\prime}$ fraction and the secondary $\gamma^{\prime}$ size (Table 3). Tertiary $\gamma^{\prime}$ precipitates were also observed on thin foils using transmission electron microscopy (TEM). These observations showed that for the five microstructures, the distribution and size of the small tertiary precipitates can be considered as equivalent.

Grain sizes were determined on crystallographic orientation maps obtained by electron backscatter diffraction (EBSD) using the linear intercept method. Cooling $\gamma^{\prime}$ precipitates were examined using a scanning electron microscope equipped with a field emission gun (SEMFEG). Multiple high resolution images were analysed (ImageJ software) to obtain the $\gamma^{\prime}$ precipitate size distribution. The equivalent circle diameter was converted from area measurement of each particle and the mean diameter was calculated from a size distribution based on 250 to about 2000 particle measurements.

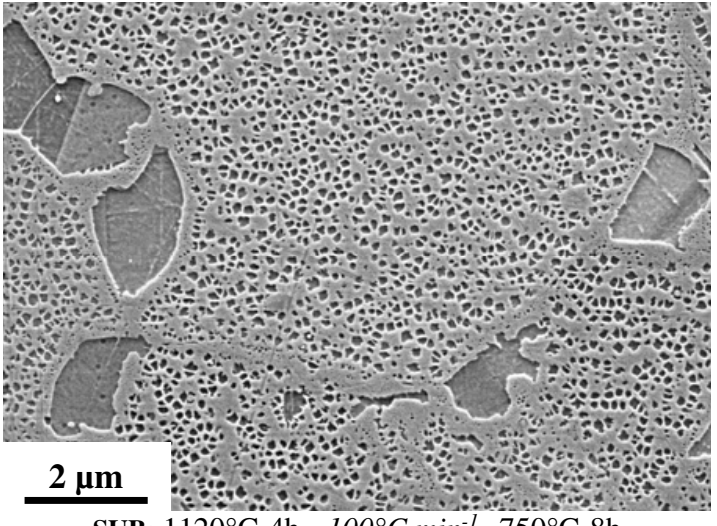

SUB: $1120^{\circ} \mathrm{C}-4 \mathrm{~h}-100^{\circ} \mathrm{C} \cdot \mathrm{min}^{-1}-750^{\circ} \mathrm{C}-8 \mathrm{~h}$

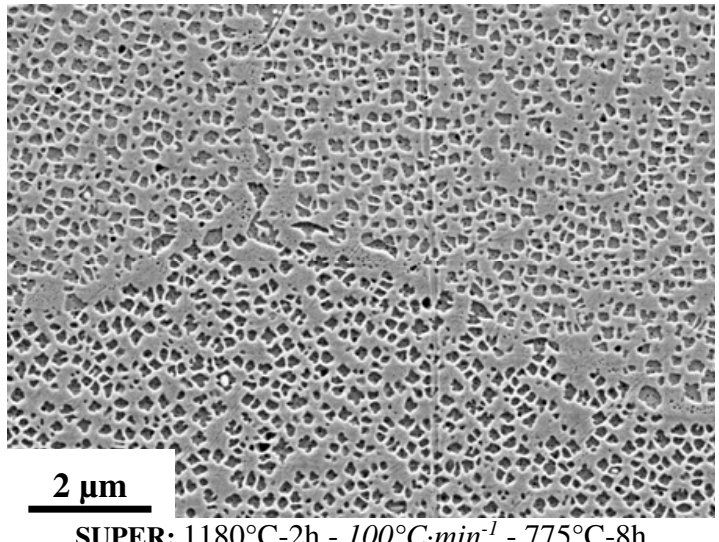

Figure 1. Effect of the solution temperature on the microstructure of SUB and SUPER HT specimens (SEM - secondary electrons).

\subsection{Effects of heat treatments on grain size}

The subsolvus solution HT produces a fine grain structure due to primary $\gamma^{\prime}$ pinning. For PM superalloys treated in the supersolvus condition, the effect is no longer effective but the grain growth is limited due to pinning at prior powder particle boundaries. For N19 alloy, the subsolvus HT leads to a fine grain size of $6 \mu \mathrm{m}$ and all the supersolvus HT to a coarser grain size of about 22-25 $\mu \mathrm{m}$, the cooling path having no effect on grain growth (Table 3 and Fig. 1).

\subsection{Effects of cooling path on secondary $\gamma^{\prime}$ size}

Secondary (or cooling) $\gamma^{\prime}$ particles precipitate from the matrix during quenching and are homogeneously distributed. As usually observed, the size of these precipitates increases as the cooling rate decreases [3-5]. As the precipitates grow (Fig. 2 and Table 3), their morphology changes from roughly cuboidal (SUB HT, SUPER and SUPER FC) to octo-cube shape (SUPER SC and SUPER TR).

The two-rate cooling HT leads to a bi-modal precipitation of secondary $\gamma^{\prime}$ precipitates (Fig. 3). The population of coarse octo-cube precipitates is assumed to nucleate during the first slow cooling step $\left(15^{\circ} \mathrm{C} \cdot \mathrm{min}^{-1}\right)$. The additional smaller secondary $\gamma^{\prime}$ precipitates is attributed to a burst of nuclei during the second and faster cooling stage $\left(100^{\circ} \mathrm{C} \cdot \mathrm{min}^{-1}\right)$. 

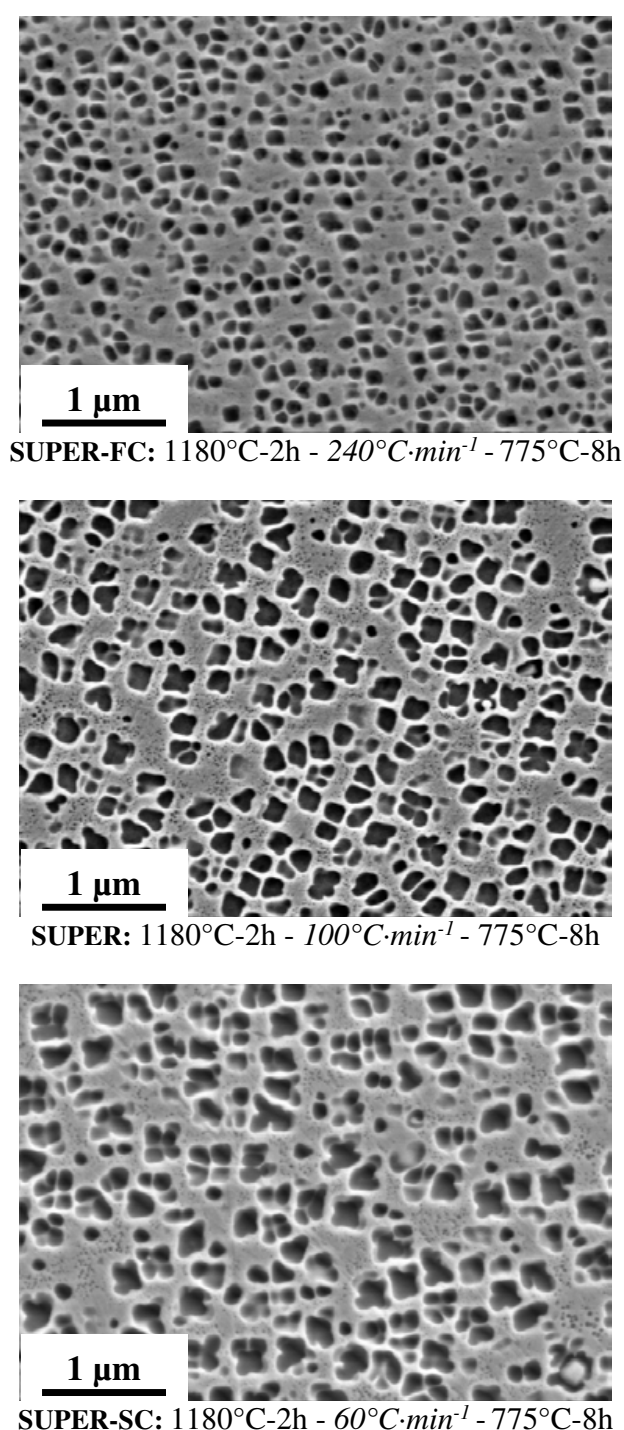

Figure 2. Effect of the cooling rate on the microstructure of supersolvus heat treated specimens (SEM - secondary electrons).

\section{Effects of heat treatments on mechanical properties}

All the mechanical testing specimens were machined from heat treated cylindrical blanks cut tangentially along the rim of the pancakes.

\subsection{Tensile strength}

Tensile tests were performed at room temperature (RT), $550{ }^{\circ} \mathrm{C}$ and $700^{\circ} \mathrm{C}$ on specimens with $20 \mathrm{~mm}$ gauge length and $4 \mathrm{~mm}$ diameter on a MTS 810 testing machine using an axial extensometer and a resistance furnace. The $0.2 \%$ yield strength $(0.2 \%$ YS), ultimate tensile strength (UTS) and elongation to rupture are given in Fig. 4 and Table 4.

Tensile data for the supersolvus microstructures (SUPER and SUPER-SC) are consistent with those previously published for SMO43 specimens after a supersolvus HT on pancake forgings (SMO43 alloy is equivalent to N19 alloy [1]).

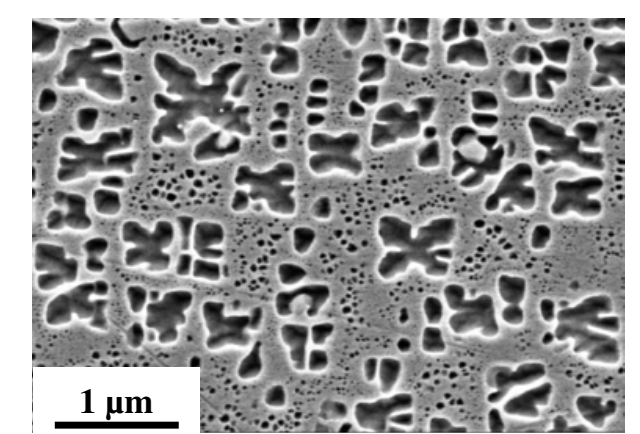

SUPER-TR: $1180^{\circ} \mathrm{C}-2 \mathrm{~h}-15^{\circ} \mathrm{C} \cdot \mathrm{min}^{-1}$ to $1080^{\circ} \mathrm{C}$ then $100^{\circ} \mathrm{C} \cdot \mathrm{min}^{-1}-750^{\circ} \mathrm{C}-8 \mathrm{~h}$

Figure 3. Effect of the two-rate cooling on the microstructure of a supersolvus heat treated specimen (SEM - secondary electrons).

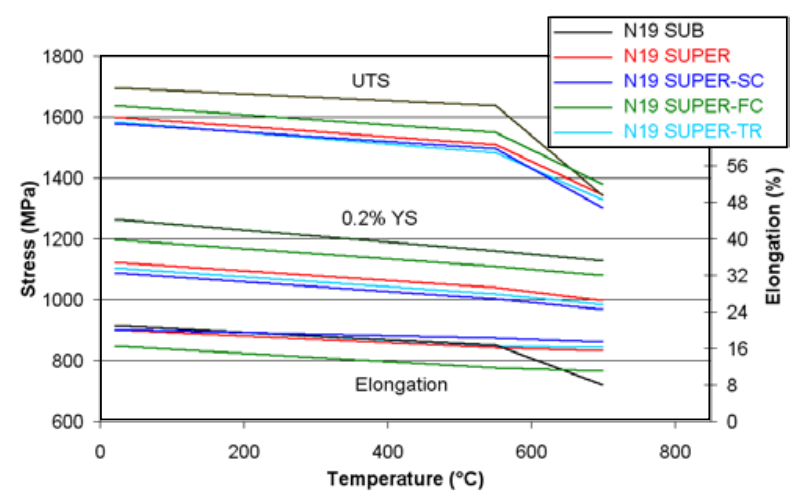

Figure 4. Tensile properties versus test temperature for the five variants of N19 alloy.

Those results agree with the usual effects of the grain and secondary $\gamma^{\prime}$ sizes: the finer the grain size or the precipitate size, the higher the tensile strengths. However, the beneficial effect of the subsolvus HT is significantly reduced at $700{ }^{\circ} \mathrm{C}$ in terms of UTS and elongation to rupture as observed for Alloy 10 [2]. It is pointed out that the presence of two populations of secondary $\gamma^{\prime}$ precipitates in the SUPER-TR HT (with one coarse precipitate population) does not dramatically affect the tensile strengths.

\subsection{Creep-rupture behaviour}

Tensile creep-rupture tests were conducted at $700{ }^{\circ} \mathrm{C}$ and at an applied stress of $700 \mathrm{MPa}$ on specimens with $17 \mathrm{~mm}$ gauge length and $3 \mathrm{~mm}$ diameter. Creep-rupture plots are compared in Fig. 5 and selected creep data are listed in Table 5.

At $700{ }^{\circ} \mathrm{C}$ and $700 \mathrm{MPa}$, the SUB HT leads to the weakest creep resistance. In spite of the fine secondary $\gamma^{\prime}$ precipitation, the fine grain size is detrimental in terms of time and elongation to rupture. It is assumed that the grain boundary sliding is significantly activated in these creep conditions. As a consequence, all the supersolvus HT lead to higher creep strengths. The beneficial effect of high cooling rates on the creep resistance has been reported in many studies $[2,3,6,7]$. This trend is confirmed when comparing the creep behaviour of the SUPER and the SUPER-FC HT specimens. It is less clear in the case of 
Table 4. Tensile properties at RT, $550^{\circ} \mathrm{C}$ and $700^{\circ} \mathrm{C}$ for the five variants of $\mathrm{N} 19$ alloy (mean value of 2 tests).

\begin{tabular}{|c|c|c|c|c|c|c|c|c|c|}
\hline & \multicolumn{3}{|c|}{ RT } & \multicolumn{3}{|c|}{$550^{\circ} \mathrm{C}$} & \multicolumn{3}{|c|}{$700^{\circ} \mathrm{C}$} \\
\hline $\begin{array}{l}\text { Heat } \\
\text { treatment }\end{array}$ & $\begin{array}{c}0.2 \% \text { YS } \\
\text { (MPa) }\end{array}$ & $\begin{array}{l}\text { UTS } \\
\text { (MPa) }\end{array}$ & $\begin{array}{c}\text { Elong. } \\
(\%)\end{array}$ & $\begin{array}{c}0.2 \% \text { YS } \\
\text { (MPa) }\end{array}$ & $\begin{array}{c}\text { UTS } \\
\text { (MPa) }\end{array}$ & $\begin{array}{c}\text { Elong. } \\
(\%)\end{array}$ & $\begin{array}{c}0.2 \% \text { YS } \\
(\mathrm{MPa})\end{array}$ & $\begin{array}{c}\text { UTS (MPa) } \\
\text { (MPa) }\end{array}$ & $\begin{array}{c}\text { Elong. } \\
(\%)\end{array}$ \\
\hline SUB & 1265 & 1695 & 21.0 & 1160 & 1637 & 16.7 & 1128 & 1341 & 8.0 \\
\hline SUPER & 1122 & 1601 & 20.1 & 1041 & 1510 & 16.2 & 997 & 1345 & 15.5 \\
\hline SUPER-SC & 1089 & 1579 & 20.1 & 1002 & 1495 & 18.3 & 967 & 1301 & 17.4 \\
\hline SUPER-FC & 1198 & 1636 & 16.6 & 1109 & 1551 & 11.8 & 1079 & 1379 & 11.1 \\
\hline SUPER-TR & 1104 & 1572 & 20.9 & 1018 & 1470 & 16.6 & 985 & 1276 & 16.2 \\
\hline
\end{tabular}

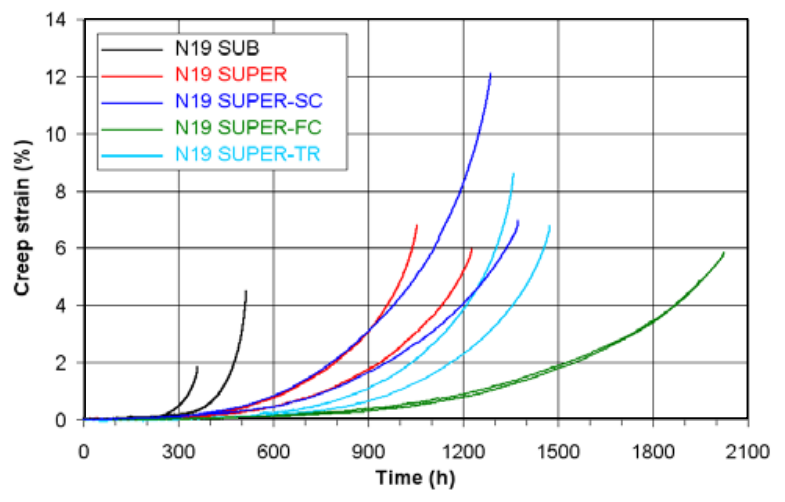

Figure 5. Creep-rupture plots at $700{ }^{\circ} \mathrm{C}$ and $700 \mathrm{MPa}$ for the five variants of N19 alloy.

the SUPER-SC HT. The cooling rates of the SUPER and the SUPER-SC HT and consequently secondary $\gamma^{\prime}$ precipitate size are relatively close (Table 3 ) which leads to similar times to $0.2 \%$ and $1 \%$ creep strain. For the SUPERTR HT, the small $\gamma^{\prime}$ precipitates between the coarse ones seem to efficiently impede the mobility of the dislocations.

\subsection{Low cycle fatigue behaviour}

Low cycle fatigue (LCF) tests were conducted at $650^{\circ} \mathrm{C}$ on SUB and SUPER HT specimens. Tests were performed at $0.7 \%$ and at $1 \%$ maximum strain range and $\mathrm{R} \varepsilon=$ $\varepsilon_{\min } / \varepsilon_{\max }=0.05$.

Figure 6 shows that, at the two different strain amplitudes, the LCF lives of the SUB HT and the SUPER HT specimens are dispersed within the same ranges. Crack initiation sites in the various specimens corresponding to both HT are the usual ones in Ni-based PM superalloys: initiation occurs from porosity, or by cleavage of a grain, or from a ceramic inclusion. However the distribution of the initiation sites according to the different types differs in SUPER HT specimens from SUB HT ones (see table in Fig. 6). Crack initiation occurs predominantly from ceramic inclusions in the SUB HT specimens whereas it happens mostly by cleavage in a grain in the SUPER HT specimens. Crack initiation from ceramic inclusions, which is the most harmful for LCF life of PM superalloy parts, accounts for only $23 \%$ of the crack initiation sites in the SUPER HT specimens against 55\% in the SUB HT ones.

\subsection{Fatigue crack growth behaviour}

Fatigue crack growth (FCG) tests were conducted on SENT (Single Edge Notched Tension) specimens. The
Table 5. Creep properties at $700^{\circ} \mathrm{C}$ and $700 \mathrm{MPa}$ for the five variants of N19 alloy (mean value of 2 tests).

\begin{tabular}{|l|c|c|c|c|}
\hline $\begin{array}{l}\text { Heat } \\
\text { treatment }\end{array}$ & $\begin{array}{c}\mathbf{t}_{\mathbf{0 . 2}} \boldsymbol{( h )} \\
(\mathbf{h})\end{array}$ & $\begin{array}{c}\mathbf{t}_{\mathbf{1}} \boldsymbol{( h )} \\
(\mathbf{h})\end{array}$ & $\begin{array}{c}\mathbf{t}_{\text {rupture }} \\
(\mathbf{h})\end{array}$ & $\begin{array}{c}\text { Elong. } \\
(\boldsymbol{\%})\end{array}$ \\
\hline SUB & 291 & 386 & 436 & 3.2 \\
\hline SUPER & 380 & 692 & 1140 & 6.4 \\
\hline SUPER-SC & 373 & 702 & 1330 & 9.6 \\
\hline SUPER-FC & 649 & 1244 & 1985 & 5.4 \\
\hline SUPER-TR & 595 & 935 & 1416 & 7.7 \\
\hline
\end{tabular}

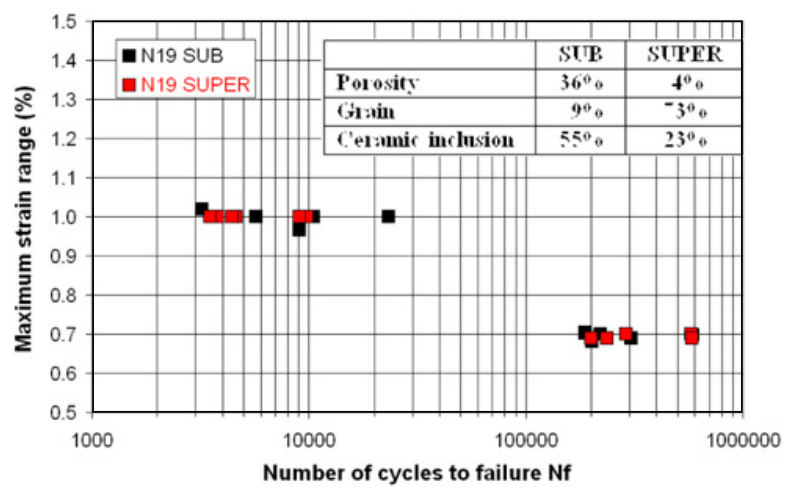

Figure 6. $\mathrm{LCF}$ results at $650{ }^{\circ} \mathrm{C}$ and $\mathrm{R} \varepsilon=0.05$ for SUB and SUPER heat treatments.

section of these specimens is rectangular, $3 \mathrm{~mm}$ thick and $12 \mathrm{~mm}$ wide. A notch, $0.9 \mathrm{~mm}$ deep and $0.2 \mathrm{~mm}$ wide, was cut by electrical discharge machining along their thickness, in the middle of the specimen length. The tip of this notch is to become the crack initiation zone during testing. Machining was done so as to place the initial crack propagation plane orthogonal to the pancake plane. A servo-hydraulic machine, fitted with a radiation furnace was used for the tests. Crack growth was measured by potential drop monitoring, the calibration of this method being made by periodical measurements of the crack length using optical microscopy. Tests were performed at $650^{\circ} \mathrm{C}$ in air according to a creep-fatigue "10-300-10" cycle consisting in a 10 second loading at constant loading rate up to the maximum load $\mathrm{F}_{\max }$, followed by a 300 second hold at this maximum load $F_{\max }$, and then unloading at constant rate down to the minimum load $\mathrm{F}_{\min }$. The loading ratio $\mathrm{F}_{\min } / \mathrm{F}_{\max }$ is 0.1 . Initial loading was calculated so as to correspond to an initial $\Delta \mathrm{K}$ between 23 to $24 \mathrm{MPa} \cdot \mathrm{m}^{1 / 2}$ which has previously been shown to cause a fatigue crack growth rate in the beginning of the Paris law domain. 


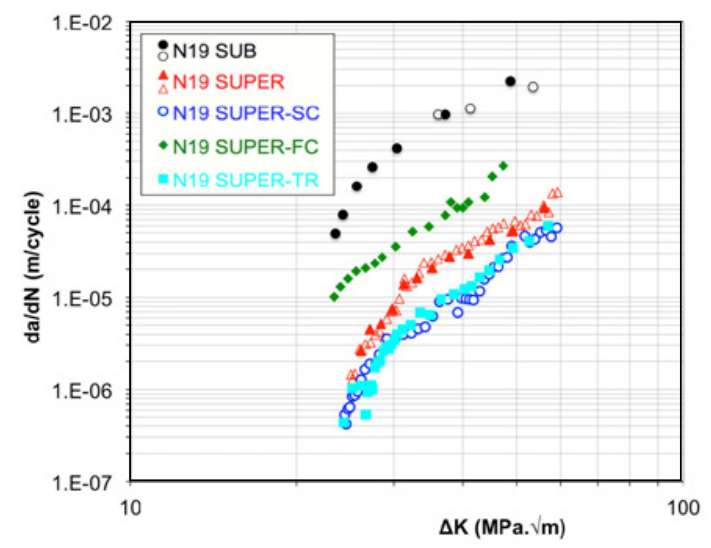

Figure 7. FCG plots at $650^{\circ} \mathrm{C}$ and "10-300-10" cycle for the five variants of N19 alloy.

The plots of da/dN versus $\Delta \mathrm{K}$ corresponding to the five selected heat treatments are displayed in Fig. 7. (Two specimens were tested for the SUB and SUPER HT and only one for the SUPER-SC, SUPER-FC and SUPER-TR HT.)

Fatigue crack growth rates (FCGR) of the supersolvus heat treated specimens (SUPER, SUPERSC, SUPER-FC and SUPER-TR HT) are at least one order of magnitude slower than the FCGR of the SUB heat-treated specimen. This effect of the supersolvus heat treatment on the FGCR is due to the increase of the grain size made possible by the complete solutioning of the primary $\gamma^{\prime}$ precipitates, which anchor the grain boundaries during the recrystallisation processes occurring during compaction and forging. Numerous studies conducted on PM Ni-based superalloys [8-10] or on conventional wrought ones [11] have shown that FCGR in air at high temperature is faster in a small grains microstructure than in a large grains one. One interpretation of this effect is based on oxidation of the grain boundaries at the tip of the crack during crack growth and the ensuing loss of resistance of these grain boundaries to crack propagation. A large grain size, by reducing the global grain boundary surface in the specimen, makes crack propagation more difficult which results in lowering the FCGR.

In the range of constant slope cooling rates covered in this study, FGCR decreases when the cooling rate decreases. The effect of the cooling rate on the microstructure concerns essentially the distribution of the secondary $\gamma^{\prime}$ precipitates, that is to say their size and, correlatively, the width of the $\gamma$ matrix channels between them: the slower the cooling rate, the larger the secondary $\gamma^{\prime}$ precipitates and the wider the channels. These channels, when large enough, are inhabited by tertiary $\gamma^{\prime}$ precipitates, the distribution of which has been optimised during the aging treatment. The decrease of the FCGR with the decrease of the constant cooling rate and then with the increase of the width of the $\gamma$ matrix channels is attributed to the capacity to relax the stress at the tip of the crack. This ability is better in a microstructure with large $\gamma$ matrix channels inhabited by small tertiary $\gamma^{\prime}$ which can be sheared (SUPER-SC), rather than in a microstructure with narrow $\gamma$ matrix channels between secondary $\gamma^{\prime}$ precipitates more difficult to shear (SUPER-FC).
In the case of the two-rate cooling HT, though the second part of the cooling stage is performed at $100{ }^{\circ} \mathrm{C} \cdot \min ^{-1}$, the resultant microstructure is characterised by features which would have been made by cooling at a lower constant rate: wide $\gamma$ matrix channels inhabited by small tertiary $\gamma^{\prime}$ are present between the large secondary $\gamma^{\prime}$ precipitates nucleated during the first part of cooling, performed at $15^{\circ} \mathrm{C} \cdot \mathrm{min}^{-1}$, and smaller secondary $\gamma^{\prime}$ precipitates nucleated during the second part of cooling, performed at $100{ }^{\circ} \mathrm{C} \cdot \mathrm{min}^{-1}$. This microstructure appears to share more similarities with the one corresponding to the SUPER-SC HT. The likeness of the plots of FCGR in the SUPER-TR specimen and in SUPER-SC HT is justified by the better ability to relax the stress at the tip of the crack in microstructures with wide $\gamma$ matrix channels inhabited by small tertiary $\gamma^{\prime}$ which is a feature common to these two microstructures.

\section{Conclusions}

As expected, the new PM superalloy N19 achieves the specifications in regard to a wide sensitivity to heat treatments, especially in supersolvus conditions. This aptitude lets consider a possible optimisation of the mechanical properties through tailored heat treatments acting on $\gamma^{\prime}$ precipitate distribution and on grain boundaries, which are known to both have a strong effect on the mechanical behaviour. For example, it is anticipated that a coarse grain microstructure achieved by supersolvus solutioning will provide better creep resistance and lower crack growth rate in dwell-time fatigue at high temperature. Up to now, the grain size remains limited to $25 \mu \mathrm{m}$ in all investigated conditions. In contrast, the distributions, sizes and morphologies of secondary and tertiary $\gamma^{\prime}$ are significantly modified by the cooling path after solutioning treatment.

The mechanical properties are consequently modified both for tensile strength with a classical strength evolution versus grain or precipitate size ("the finest, the best") and for creep, in which very good resistances can be observed at $700^{\circ} \mathrm{C}$ in spite of a limited grain size. Preliminary LCF tests show a very small influence of heat treatment between subsolvus and supersolvus on fatigue lives at $650{ }^{\circ} \mathrm{C}$ but the rate of crack initiation from ceramic inclusions is significantly decreased in the supersolvus heat treated alloy, which can be correlated to a larger grain size. Finally, the crack propagation rate at $650{ }^{\circ} \mathrm{C}$ with dwell time cycles is closely dependent on grain size and $\gamma^{\prime}$ distributions. Very low crack growth rates were reported for two supersolvus heat treatments.

Definitely, N19 confirms its quite interesting potential for disk applications thanks to its high level of mechanical properties. An upgraded material with coarser grain microstructure could exhibit better creep and crack propagation resistances as well as a reduced propensity for crack nucleation from inclusions under fatigue loading. More fatigue data will be soon obtained to consolidate the LCF curves. In parallel, the route enabling grain coarsening up to 50-70 $\mu \mathrm{m}$ will be investigated in a future research programme.

The French Ministry of Defence is gratefully acknowledged for financial support. 


\section{References}

[1] J.-Y. Guédou, I. Augustins-Lecallier, L. Nazé, P. Caron, D. Locq, Superalloys 2008 21-30 (2008)

[2] G. Raisson., J.H. Davidson, High Temperature Materials for Power Engineering 1405-1416 (1990)

[3] J. Mao, K.-M. Chang, W. Yang, K. Ray, S.P. Vaze, D.U. Furrer, Metall Mater Trans A 32A 2441-2452 (2001)

[4] J. Mao, K.-M. Chang, W. Yang, D.U. Furrer, K. Ray, S.P. Vaze, Mater Sci Eng A A332 318-329 (2002)

[5] J. Gayda, P. Kantzos, J. Telesman, NASA Report TM-2003-212473 (2003)
[6] G.B. Viswanathan, P.M. Sarosi, M.F. Henry, D.D. Whitis, W.W. Milligan, M.J. Mills, Acta Mater 53 3041-3057 (2005)

[7] T.P. Gabb, J. Gayda, J. Telesman, A. Garg, Superalloys 2008 121-130 (2008)

[8] J. Telesman, T.P. Gabb, J. Gayda, P. Bonacuse, A. Prescenzi, Superalloys 2004 215-224 (2004)

[9] J. Gayda, T.P. Gabb, P. Kantzos, Superalloys 2004 323-329 (2004)

[10] R.J. Mitchell, J.A. Lemsky, R. Ramanathan, H.Y. Li, K.M. Perkins, L.D. Connor, Superalloys 2008 347356 (2008)

[11] N.J. Hide, M.B. Henderson, P.A.S. Reed, Superalloys $2000495-503$ (2000) 